\title{
Association Between CD30 Expression and EBV-DNA Detection Status With ABVD Chemotherapy Response in Classical Hodgkin Lymphoma Patients
}

\author{
Bethy S Hernowo ${ }^{1, *}$, Hermin A Usman ${ }^{2}$, Zahra Nurusshofa $^{3}$, Etis Primastari ${ }^{4}$, Aryanti $^{5}$ \\ ${ }^{1,2}$ Department of Anatomic Pathology, Padjadjaran University, Bandung, Indonesia \\ ${ }^{3}$ Anatomic Pathology Study Program, Faculty of Medicine, Padjadjaran University, Bandung, Indonesia \\ Faculty of Medicine, Muhammadiyah University of Prof.DR. Hamka, Tangerang, Indonesia \\ ${ }^{4,5}$ Anatomical Pathology Study Program Faculty of Medicine, Padjadjaran University, Bandung, Indonesia \\ ${ }^{*}$ Corresponding author. Email: etis16001@mail.unpad.ac.id
}

\begin{abstract}
CD30 is expressed in Hodgkin lymphoma (HL). To date, research efforts have focused on understanding its contribution to lymphomagenesis through anti-apoptotic mechanisms, and its effect on cell survival. It has been suggested that Epstein-Barr virus (EBV) plays a role in the pathogenesis of positive cases, as an early event in HL development. The presence of EBV is associated with prognosis. More than $40 \%$ of Hodgkin lymphoma (HL) patients are chemoresistant and show early relapse. The purpose of this study is to determine if there is an association between CD30 and EBV-DNA in HL with doxorubicin, bleomycin, vinblastine and dacarbazine (ABVD) regimen response therapies. This study is a cross-sectional study that was conducted at 3 hospitals in Bandung, Indonesia. We analyzed paraffin sections from 60 cases with histologically diagnosed with Classical Hodgkin lymphoma. ABVD chemotherapy response was evaluated by RECIL criteria. Detection of EBV-DNA by Real-Time PCR and CD30 expression using immunohistochemistry with semiquantitative evaluation was performed on all samples. All data were analyzed using a Chi-Square test with a p-value $<0.05$ for significant levels. From 60 cases, 28 cases (46,7\%) showed a complete/partial response and 32 cases $(53,3 \%$ showed no response to the ABVD regimen. EBV-DNA were present in 33 cases (55\%), 10 cases from the complete/partial response group and 23 cases from the no response group. Low CD30 expression distribution $(\leq 25 \%)$ dominated the complete response group $(68 \%)$, whereas high CD30 distribution (>25\%) dominated the nonresponse group (68,7\%). The results showed a statistically significant EBV-DNA detection status ( $\mathrm{p}=0.005)$ and CD30 expression $(\mathrm{p}=0.009)$ between the complete/partial response and nonresponse groups. In conclusion, the ABVD chemotherapy response of $\mathrm{CHL}$ is associated with CD30 expression and EBV-DNA infection.
\end{abstract}

Keywords: “CD30”, “EBV”, “ABVD”, “Classical Hodgkin Lymphoma”

\section{INTRODUCTION}

Hodgkin lymphomas (HL) are lymphoid malignancies that are composed of large mononuclear and multinucleated cells, with a cellular background rich in inflammatory cells ${ }^{1}$. In Europe and the US, HL is present in 2-3 per 10,000 people. Age distribution is bimodal, occurring in early adulthood (20-30 years) and late adulthood (over 55 years). ${ }^{2}$ In terms of histological structure, $\mathrm{HL}$ are divided into two major categories: nodular lymphocyte predominant HL (NLPHL) and classic HL (CHL). 90\% of all HL cases are classic HL ${ }^{1}$.

Previous studies have revealed that after receiving primary therapy with ABVD chemotherapy regimens (doxorubicin, bleomycin, vinblastine, and dacarbazine), over $80 \%$ of patients with advanced Hodgkin lymphoma (HL) enter complete remission; however, approximately $40 \%$ of patients relapse over time and require additional therapy. Between $66 \%$ and $89 \%$ of patients respond to these regimens, meaning that the non-response rate for refractory and relapsed HL patients is $10 \%-30 \%$. ${ }^{3}$. Salvage chemotherapy followed by high-dose therapy (HDT) and autologous stem cell transplantation (ASCT) is only able to cure $50 \%$ of patients ${ }^{4}$.

The Epstein-Barr virus (EBV) is a human herpes gamma-1 virus. EBV is involved in the pathogenesis of many emerging B-cell lymphomas, including Burkitt's lymphoma, Natural killer (NK)/T cell lymphoma, diffuse large B cell lymphoma (DLBCL) and Hodgkin's lymphoma ${ }^{5}$. Epidemiological studies indicate that CHL infects more than $90 \%$ of individuals who have previously been exposed to Epstein-Barr virus (EBV) who reach adulthood ${ }^{6}$. Latent EBV genomes express five EBV-encoded nuclear antigens (EBNA) and two latent membrane proteins (LMPs): EBVencoded small RNA (EBER) and non-transcribed BART (BamHI-A region rightward transcript) RNAs ${ }^{7}$. The 
development and survival of Hodgkin Reed Sternberg cells can also be encouraged by EBNA1 ${ }^{8}$.

One of several tumor necrosis factor receptors (TNFR) is Cluster of Differentiation 30 (CD30). Malignancies have recorded the highest rate of elevated CD30 expression in diseased tissue. Hodgkin lymphoma and ALCL are two of the foremost malignancies with elevated CD30 expression ${ }^{9}$. The neoplastic cells in Hodgkin's lymphoma are often CD30-positive, and CD30 expression on the surface of Reed-Sternberg cells associated with the size and invasiveness of the tumor ${ }^{10}$. Due to the variable expression of CD30, the focus of previous research has been on examining the pathogenesis of CD30 upregulation, its contribution to lymphomagenesis through anti-apoptotic mechanisms, and its effect on cell survival ${ }^{11}$. Due to the fact that its expression is often limited to particular disease states, CD30 has become an important molecule in the field of targeted therapy ${ }^{9}$.

The synergistical implications of EBV infection on the function of Cluster of Differentiation (CD30) is not known. However, $\mathrm{Hu}$ et al.'s research revealed considerately worse OS and PFS in patients with $\mathrm{CD}^{+} 0^{+} \mathrm{EBV}^{+}$DLBCL compared to those with $\mathrm{CD}^{+} 0^{+} \mathrm{EBER}^{-}$DLBCL. There is still limited data on Classical Hodgkin Lymphoma cases ${ }^{12}$.

Therefore, we have attempted to evaluate the frequency of CD30 expression and EBV-DNA status in Hodgkin lymphoma patients, and its relationship with ABVD chemotherapy.

\section{MATERIAL AND METHODS}

\subsection{Study design}

The study is a cross-sectional following a retrospective design and involving 60 cases of classical Hodgkin lymphoma diagnosed between 2014 and 2019. The data for all cases data were re-evaluated and tumor biopsies reexamined focusing on histology. Immunohistochemistry staining of CD30 was performed on all samples. EBV-DNA presence was identified. Tumor stage and ABVD chemotherapy response were evaluated by an haematooncologist (according to RECIL criteria) and the relevant information taken from patient's medical records.

\subsection{Patients and ethical approval}

Data were retrieved from 60 consecutive patients whose tissue biopsies were examined by the Anatomical Pathology Departements at Hasan Sadikan General Hospital, Santosa Hospital and Advent Hospital in Bandung, Indonesia, between 2014-2019, and treated with ABVD chemotherapy. From these cases, the original slide and formalin-fixated parafin-embedded (FFPE) primary biopsy material from the cancer lesions were retrieved from the archives. Patient records were reviewed for age, sex, cancer stage and ABVD chemotherapy response. Stage were assessed according to Ann-Arbor staging and chemotherapy response was evaluated using RECIL criteria. Ethical approval was granted by the research ethics committee at Padjadjaran University Bandung (2019/1012). In accordance with the ethical approval, informed consent was not required due to this being an examination of historical biopsy material.

\subsection{Histopathologic review}

All histological slides were reviewed and classified according to the World Health Organization (WHO) Classification of tumors of Haematopoietic and Lymphoid Tissues (2017 edition) which categorizes CHL into four histological subtypes, i.e. nodular sclerosis (NS), mixed cellularity (MC), lymphocyte rich (LR) and lymphocyte depletion (LD). The pathologists (B.S and H.A.U) were unaware of the outcome of EBV-DNA analyses, while performing the classification.

\subsection{Immunohistochemistry of CD30}

Paraffin sections were stained using the labeled streptavidin biotin immunoperoxide complex method, using the Starr Trek Universal HRP Detection system (Biocare Medical, California, USA). The primary antibody used was CD30 using a mouse monoclonal antibody from Biocare Medical (California, USA). As the positive control, we used tonsil tissue and for the negative control we used the same FFPE sample but we eliminate the antibody reaction. The CD30 immunohistochemistry results were scored by 2 pathologists (BTS and HAU) on a 3-tiered scale (1+: $1-25 \%$ positive HRS cells, $2+26-75 \%$ positive HRS cells and $3+$ 76-100\% positive HRS cells), then divided into low (+1 ) and high $(+2$ and +3$)$ categories.

\section{5. $E B V-D N A$ detection}

Sections of FFPE blocks were prepared. They were cut into four $5 \mu \mathrm{m}$ thick section. These dissected tumor tissues were then put into $1.5 \mathrm{ml}$ microcentrifuge tubes, and DNA extracted and purified using Quick-DNA ${ }^{\mathrm{TM}}$ FFPE Kits (Zymo Research, California, USA). After purification, DNA template concentration was counted for every sample. The data was used to equalize the concentration (15 ng $\mathrm{DNA} / \mu \mathrm{l})$.

From each sample, $10 \mu 1$ was analyzed for the quantity of EBV DNA (single copy gene encoding the Epstein-Barr virus Nuclear Antigen 1 (EBNA1)) by the use of a commercial kit (EBV/ISIN/100, GeneProof, Brno, CZ) for real time PCR (Rotor-gene, Qiagen). 10 $\mu \mathrm{l}$ sample and $30 \mu \mathrm{l}$ MasterMix were added into the PCR tubes. During PCR preparation, all components were kept at $+2^{\circ} \mathrm{C}$ to $+8^{\circ} \mathrm{C}$. There are three major steps that make up each cycle in a qPCR reaction. Reactions are run for 40 cycles. qPCR steps are as follows: denaturation $95^{\circ} \mathrm{C}$ for $5 \mathrm{~s}$, annealing $55^{\circ} \mathrm{C}$ for $40 \mathrm{~s}$ and extension $72^{\circ}$ for $20 \mathrm{~s}$.

For quantification, we made standard curve (included in the kit) from $10 \times 10^{1}$ to $10 \times 10^{4}$ copies/ $\mu$ l. Quantification was extrapolated from a linear regression standard curve. 


\subsection{Statistics}

A Chi-squared test was performed to explore the association between CD30 expression and ABVD chemotherapy response, and EBV-DNA status and ABVD chemotherapy response. All statistical analyses were performed using SPSS version 24.0 for Windows, and $p$ values less than 0.05 were considered significant.

\section{RESULTS}

The clinicopathological features of the 60 cases are listed in Table 1 . The median age at diagnosis was 39.5 years (ranging from 5-76 years). The male to female (MF) ratio was 1.14:1. Mixed Cellularity Classical Hodgkin Lymphoma was the most common subtype (30\% of all cases), slightly higher than Lymphocyte Rich followed by Nodular Sclerosis and Lymphocyte Depleted subtypes (28.3\%, $25 \%$ and $16.7 \%$ of all cases, respectively). Most patients were classified as stage III $(41.6 \%)$ according to Ann Arbor criteria.

Table 1. Sample Characteristics

\begin{tabular}{lc}
\hline Variable & $\mathbf{N}=\mathbf{6 0}$ \\
\hline Age (years) & 39.50 \\
Median & $5-76$ \\
Range (min-max) &
\end{tabular}

$\begin{array}{ll}\text { Sex } & \\ \text { Male } & 32(53.3 \%) \\ \text { Female } & 28(46.7 \%)\end{array}$

\section{Histological subtype}

MCCHL

NSCHL

LRCHL

$17(28.3 \%)$

LDCHL

$10(16.7 \%)$

$\begin{array}{lc}\text { Stage } & \\ \text { I } & 4(6.7 \%) \\ \text { II } & 16(26.7 \%) \\ \text { III } & 25(41.6 \%) \\ \text { IV } & 15(25 \%)\end{array}$

A comparison between patient characteristics and CD30 expression can be seen in Table 2. Statistical tests showed that there was no significant association between age, gender, histological subtype and tumor stage and CD30 expression ( $\mathrm{p}$ value $>0.05$ ). In the table, it can be seen that cases in the High CD30 category had a mean age of 39.26 years, and were more common in the male gender, the Nodular Sclerosis histological subtype and stage III tumors.
Table 2. Distribution of age, sex, histological subtypes and stage by CD30 expression

\begin{tabular}{|c|c|c|c|}
\hline Variable & $\begin{array}{c}\text { CD30 } \\
(\text { low) } \\
(\mathbf{N}=29)\end{array}$ & $\begin{array}{c}\text { CD30 } \\
\text { (high) } \\
(\mathbf{N}=\mathbf{3 1})\end{array}$ & p value \\
\hline \multicolumn{4}{|l|}{ Age (years) } \\
\hline Mean & 40.66 & 39.26 & 0.762 \\
\hline$(95 \% \mathrm{CI})$ & $\begin{array}{c}(33.66- \\
47.65)\end{array}$ & $\begin{array}{c}(32.98- \\
45.54)\end{array}$ & \\
\hline \multicolumn{4}{|l|}{ Sex } \\
\hline Male & $14(43.8 \%)$ & $18(56.2 \%)$ & 0.605 \\
\hline Female & $15(53.6 \%)$ & $13(46.4 \%)$ & \\
\hline \multicolumn{4}{|c|}{ Histological subtype } \\
\hline MCCHL & $9(50 \%)$ & $9(50 \%)$ & 0.353 \\
\hline NSCHL & $5(33.3 \%)$ & $10(66.7 \%)$ & \\
\hline LRCHL & $8(47.1 \%)$ & $9(52.9 \%)$ & \\
\hline LDCHL & $7(70 \%)$ & $3(30 \%)$ & \\
\hline \multicolumn{4}{|l|}{ Stage } \\
\hline I & $2(50 \%)$ & $2(50 \%)$ & 0.402 \\
\hline II & $10(62.5 \%)$ & $6(37.5 \%)$ & \\
\hline III & $10(40 \%)$ & $15(60 \%)$ & \\
\hline IV & $7(46.7 \%)$ & $8(53.3 \%)$ & \\
\hline
\end{tabular}

A comparison between patient characteristics and EBVDNA status can be seen in Table 3. Statistical tests showed that there was no significant association between age, gender, histological subtype and tumor stage and EBVDNA status ( $p$ value $>0.05$ ). In the table, it can be seen that cases that were EBV-DNA positive had a median age of 42 years, and were more common in male gender, the Mixed Cellularity histological subtype and stage III tumor.

The association between CD30 expression and ABVD chemotherapy response can be seen in Table 4. Statistical tests showed that there is a significant association between CD30 expression and ABVD chemotherapy response ( $\mathrm{p}$ value $=0.009)$ which means that $\mathrm{CD} 30$ expression and ABVD chemotherapy response are associated with each other. In the response group, $67,9 \%$ were cases with lowexpression of CD30 and in non-response group, $68,7 \%$ were cases with high-expression of CD30.

Table 3. Distribution of age, sex, histological subtypes and stage by EBV-DNA status

\begin{tabular}{|c|c|c|c|}
\hline Variable & $\begin{array}{l}\text { EBV- } \\
\text { DNA } \\
\text { Positive } \\
(\mathbf{N}=33)\end{array}$ & $\begin{array}{c}\text { EBV- } \\
\text { DNA } \\
\text { Negative } \\
(\mathbf{N}=\mathbf{2 7})\end{array}$ & p value \\
\hline \multicolumn{4}{|l|}{ Age (years) } \\
\hline $\begin{array}{l}\text { Median } \\
\text { Range } \\
\text { (min-max) }\end{array}$ & $\begin{array}{c}42 \\
(17-75)\end{array}$ & $\begin{array}{c}33 \\
(5-76)\end{array}$ & 0.135 \\
\hline
\end{tabular}




\begin{tabular}{|c|c|c|c|}
\hline Variable & $\begin{array}{c}\text { EBV- } \\
\text { DNA } \\
\text { Positive } \\
(\mathbf{N}=\mathbf{3 3})\end{array}$ & $\begin{array}{c}\text { EBV- } \\
\text { DNA } \\
\text { Negative } \\
(\mathbf{N}=\mathbf{2 7})\end{array}$ & p value \\
\hline \multicolumn{4}{|l|}{ Sex } \\
\hline Male & $20(62.5 \%)$ & $12(37.5 \%)$ & 0.212 \\
\hline Female & $13(46.4 \%)$ & $15(53.6 \%)$ & \\
\hline \multicolumn{4}{|c|}{ Histological subtype } \\
\hline MCCHL & $11(61.1 \%)$ & $7(38.9 \%)$ & 0.730 \\
\hline NSCHL & $8(53.3 \%)$ & $7(46.7 \%)$ & \\
\hline LRCHL & $10(58.8 \%)$ & $7(41.2 \%)$ & \\
\hline LDCHL & $4(40 \%)$ & $6(60 \%)$ & \\
\hline \multicolumn{4}{|l|}{ Stage } \\
\hline I & $2(50 \%)$ & $2(50 \%)$ & 0.916 \\
\hline II & $10(62.5 \%)$ & $6(37.5 \%)$ & \\
\hline III & $13(52 \%)$ & $12(48 \%)$ & \\
\hline IV & $8(53.3 \%)$ & $7(46.7 \%)$ & \\
\hline
\end{tabular}

Table 4. Association between CD30 expression and ABVD chemotherapy response

\begin{tabular}{lccc}
\hline \multicolumn{4}{c}{ ABVD Chemotherapy } \\
Variable & $\begin{array}{c}\text { Response } \\
(\mathbf{N = 2 8})\end{array}$ & $\begin{array}{c}\text { Non-response } \\
(\mathbf{N}=32)\end{array}$ & p value \\
\hline \multicolumn{3}{c}{ CD 30 expression } & \\
High (>25\%) & $9(29 \%)$ & $22(71 \%)$ & 0.009 \\
$(\mathrm{~N}=31)$ & & & \\
Low $(\leq 25 \%)$ & $19(65.5 \%)$ & $10(34.5 \%)$ & \\
$(\mathrm{N}=29)$ & & & \\
\hline
\end{tabular}

The association between EBV-DNA status and ABVD chemotherapy response can be seen in Table 5. Statistical tests showed that there is a significant association between EBV-DNA status and ABVD chemotherapy response ( $p$ value $=0.005)$ which means that EBV-DNA status and ABVD chemotherapy response are associated with each other. In the response group, $66,7 \%$ of cases were EBVDNA negative and in the non-response group, $69,7 \%$ of cases were EBV-DNA positive.

Table 5. Association between EBV-DNA and ABVD chemotherapy response

\begin{tabular}{lccc} 
Variable & $\begin{array}{c}\text { ABVD Chemotherapy } \\
\text { Response } \\
(\mathbf{N = 2 8})\end{array}$ & $\begin{array}{c}\text { Non- } \\
\text { response } \\
(\mathbf{N}=32)\end{array}$ & p value \\
\hline $\begin{array}{l}\text { EBV DNA } \\
\text { Positive } \\
(\mathrm{N}=33)\end{array}$ & $10(30.3 \%)$ & $23(69.7 \%)$ & 0.005 \\
$\begin{array}{l}\text { Negative } \\
(\mathrm{N}=27)\end{array}$ & $18(66.7 \%)$ & $9(33.3 \%)$ & \\
\hline
\end{tabular}

After multivariate testing, the variable that most influenced the ABVD chemotherapy response was the CD30 expression variable, displaying because it has the lowest $p$ value and an OR value that is greater than the EBVDNA variable. Therefore, it can be concluded that, simultaneously, CD30 expression is more dominant than EBV-DNA status in affecting ABVD chemotherapy response.

Table 6. Multivariate analysis of ABVD chemotherapy response

\begin{tabular}{ccccccc}
\hline Variable & B & df & Nilai & OR & \multicolumn{2}{c}{ CI 95\% } \\
& & & $\mathbf{P}$ & & Lower & Upper \\
\hline CD30 & 1.539 & 1 & 0.010 & 4.661 & 1.446 & 15.020 \\
Histoscore & & & & & & \\
EBV-dna & 1.530 & 1 & 0.011 & 4.616 & 1.427 & 14.928 \\
\hline
\end{tabular}

\section{DISCUSSION}

There is a striking variance in the rate of EBV infection in patients with CHL. According to previous studies, the range of EBV incidences is between $31.8 \%$ to up to $74.2 \%$ in different countries. ${ }^{13,14}$ The EBV frequency in this study was $55 \%$. Likely causes of the high variability in EBV prevalence include ethnic background and genetic variation. In accordance with previous findings, male participants and the MCCHL subtype in the present study showed higher but not significant incidences of EBV-positive cells..$^{6,15,16}$ The majority of cases in the current study were advanced (III and IV stage), according to Ann Arbor classification with Cotswold modification. ${ }^{17}$

The first-line chemotherapy regimen for treating HL is ABVD. ${ }^{18}$ The response rate to ABVD chemotherapy in our study was low (46.67\%) compared to studies in Serbia $(83.8 \%)$, Australia $(96 \%)$ and Italy $(79 \%)$. EBV negative cases had a slightly higher response rate $(69.7 \%)$ than EBV positive cases (66.7\%). A similar finding was also made in Murray et al.'s study, in which EBV negative cases were more responsive to chemotherapy $(94.17 \%)$ than EBV positive cases (90.24\%). ${ }^{19}$ The pathogenesis of Hodgkin's lymphoma may be a factor in the variance in chemotherapy responses.

The pathogenesis of Classical Hodgkin Lymphoma (CHL) is still unclear, partly due to the rarity and difficulty in analyzing Hodgkin and Reed-Stenberg (HRS) cells. The current study reveals that the emergence of different pathogenetic pathways is triggered by different rates of viral infections, genetic alterations, and interactions with microenvironmental components. HRS cells are imperative in regulating the microenvironment milieu associated with HL. The findings indicate complexities in communication between the tumor cells and the reactive infiltrate of the microenvironment and the occurrence of multiple mechanisms, meaning that CHL is extremely heterogeneous. ${ }^{20}$

Hodgkin and Reed-Stenberg (HRS) cells and recruited immune and stromal cells produce a complex and dense network of signals mediated by direct cell contact and soluble mediator synthesis. Most of these signals have final 
effect in the delivery of a prosurvival feedback to HRS cells. These include the engagement of surface CD30 molecules expressed on HRS cells by CD30L expressed on B lymphocytes, granulocytes, macrophages, and mast cells. ${ }^{21}$ The current study found high CD30 expression in nonresponse patients $(71 \%)$, and low CD30 expression in response patient $(65.5 \%)$. In another study, a high density of CD30 was also found to be present in patients with relapsed or refractory Hodgkin's lymphoma. ${ }^{22,23}$ According to Flangea et al., CD30 expression increases simultaneously with the progression of the disease. ${ }^{10} \mathrm{Su}$ et al. concluded that Hodgkin Reed-Stenberg cells are able to inhibit the proliferation and activation of T cells through CD30-related interactions. CD30-related interactions result in an ineffective antitumor immunity, which clearly favors the growth and survival of the tumor cells. ${ }^{24}$ Van der Weyden et al. also found that the effects of CD30 are mediated using several diverse signaling pathways, which put together benefit the survival of the cells on which CD30 is upregulated. Trimerization and signal mediation through tumor necrosis factor receptor associated proteins (TRAF) is caused by stimulation of the CD30 molecule, specifically TRAF2 to stimulate the nuclear factor-kappa B (NFkB) pathway. Furthermore, CD30 ligation is also signaled by mitogen-activated protein kinase (MAPK) pathways, including ERK1 and ERK2, which have diverse antiapoptotic and pro-survival benefits in the neoplastic cell. ${ }^{11}$

The inflammatory cell that infiltrates the tumor microenvironment displays prominent interactions with HRS cells and stimulates the production of molecules that support their growth and survival, including programmed death 1 (PD-1). ${ }^{25,26}$ EBV stimulates the production of many cytokines and chemokines by HRS cells, contributing to the peculiar microenvironment. HRS cells also produce immunosuppressive factors including PD-L1, which may inhibit cytotoxic T-cells from responding to EBV-infected HRS Cells. This latter finding indicates that in order to survive and grow, HRS cells evade immunosurveillance and interact with immune cells within the tumor microenvironment ${ }^{23}$. Higher PD-LI expression levels were found in EBV-positive cases, suggesting that viral infections further upregulate PD-L1. ${ }^{28}$

$\mathrm{Wu}$ et al. suggest that, by reducing their proapoptotic potential, PD-L1 overexpression renders tumor cells resistant to certain chemotherapy drugs. The study also suggests that chemoresistance as a result of PD-L1 is reliant on and requires an ERK/ MAPK pathway through the association of PD-L1 with DNA-PKcs. DNA-PKcs can activate MAPK/ERK pro survival signaling pathways. Increased activation of ERK in tumor cells was caused by overexpression of PD-L1, and p38 MAPK activation reduced by PD-L1 deficiency. Decreased activation of p38 MAPK consequently led to reduced expression of Bcl-2, a pro survival molecule. $^{29}$

In addition to playing a critical role in apoptosis, PD-L1, BCL (B Cell Lymphoma) proteins, as family member mutations, interfere with normal programmed cell death. Almost $38 \%$ of cases reported $\mathrm{Bcl}-2$ protein expression in Hodgkin Lymphoma, and Reed Sternberg cells. Another study revealed that Reed Sternberg cells were bcl-2 positive in $62 \%$ of Hodgkin Lymphoma cases. According to Chetty et al.'s study, most Reed Sternberg-like cells encountered in post-transplant lymphoproliferative disorders are strongly positive for both EBV and bcl-2 protein. ${ }^{30} \mathrm{EBV}$-positive expression was found to result in the induction of $\mathrm{Bcl}-2$, and $\mathrm{Bcl}-2$ expression to confer a survival function upon the cells. $^{31}$ Angelica Gamboa-Cedeño et al.'s study revealed that BCL2 expression rate correlated with a lack of response to conventional therapy and both early and late disease progression in CHL. ${ }^{32,33}$ Further research is required to determine the effect of PD-L1 and BCL2 in responses to $\mathrm{ABVD}$ and other chemotherapy regimens.

\section{CONCLUSION}

Low CD30 expression distribution dominated the complete response group, whereas high CD30 distribution dominated the nonresponse group. The results showed a statistically significant EBV-DNA detection status $(p=0.005)$ and CD30 expression $(p=0.009)$ between the complete/partial response and nonresponse groups. In conclusion, In conclusion, CHL responses to ABVD chemotherapy are found to be linked to CD30 expression and EBV-DNA status.

\section{AUTHORS' CONTRIBUTIONS}

BSH and HAU conceptualized and designed of the study, revised the manuscript critically for important intellectual content, and approved manuscript critically for important intellectual content.

ZN conception and designed the study, Acquired data, analyzed and interpreted of data, draft the manuscript, revised the manuscript critically for important intellectual content, and approved of the version of the manuscript critically for important intellectual content.

EP and A acquired data, analyzed and interpretated the data, draft the manuscript, revised themanuscript critically for important intellectual content

\section{ACKNOWLEDGMENTS}

This research was supported by the Ministry of Research and Technology of the Republic of Indonesia.

\section{REFERENCES}

[1] S. H. Swerdlow, E Campo., N. L. Haris., E. S. Jaffe. Hodgkin Lymphoma. . WHO Classification of Tumours of Haematopoietic and Lymphoid Tissues Lyon: International Agency for Research on Cancer Press 2017. p. 423-41.

[2] A. Younes, Handbook of Lymphoma. Switzerland: Springer International Publishing 2016.

[3] A. S. Gerrie, M. M. Power, J. D. Shepherd, K. J. Savage, L. H. Sehn, and J. M. Connors, "Chemoresistance can be overcome with high-dose chemotherapy and autologous stem-cell transplantation for relapsed and refractory Hodgkin lymphoma," Ann Oncol, vol. 25, no. 11, pp. 2218-23, Nov 2014. 
[4] Y. Wang, G. S. Nowakowski, M. L. Wang, and S. M. Ansell, "Advances in CD30- and PD-1-targeted therapies for classical Hodgkin lymphoma," Journal of Hematology \& Oncology, vol. 11, no. 1, p. 57, 2018/04/23 2018 .

[5] A. Okamoto et al., "The prognostic significance of EBV DNA load and EBER status in diagnostic specimens from diffuse large B-cell lymphoma patients," (in eng), Hematol Oncol, vol. 35, no. 1, pp. 87-93, Mar 2017.

[6] A. H. J. F. M. Campos et al., "Frequency of EBV associated classical Hodgkin lymphoma decreases over a 54-year period in a Brazilian population," Scientific Reports, vol. 8, no. 1, p. 1849, 2018/01/30 2018.

[7] M.-S. Kang and E. Kieff, "Epstein-Barr virus latent genes," Experimental \& Molecular Medicine, vol. 47, no. 1, pp. e131-e131, 2015/01/01 2015.

[8] P. G. Murray and L. S. Young, "An etiological role for the Epstein-Barr virus in the pathogenesis of classical Hodgkin lymphoma," Blood, vol. 134, no. 7, pp. 591596, Aug 152019.

[9] E. M. Sotomayor, K. H. Young, and A. Younes, "Clinical roundtable monograph: CD30 in lymphoma: its role in biology, diagnostic testing, and targeted therapy," (in eng), Clin Adv Hematol Oncol, vol. 12, no. 4 Suppl 10, pp. 1-22, Apr 2014.

[10] C. Flangea et al., "CD30 expression utilization for the accuracy of classical Hodgkin's lymphoma staging," (in eng), Rom J Morphol Embryol, vol. 47, no. 2, pp. 1137, 2006.Gerrie AS, Power MM, Shepherd JD, Savage KJ, Sehn LH, Connors JM. Chemoresistance can be overcome with high-dose chemotherapy and autologous stem-cell transplantation for relapsed and refractory Hodgkin lymphoma. Ann Oncol. 2014 Nov;25(11):2218-23.

[11] C. A. van der Weyden, S. A. Pileri, A. L. Feldman, J. Whisstock, and H. M. Prince, "Understanding CD30 biology and therapeutic targeting: a historical perspective providing insight into future directions," (in eng), Blood Cancer J, vol. 7, no. 9, p. e603, Sep 8 2017.

[12] [12] S. Hu et al., "CD30 expression defines a novel subgroup of diffuse large B-cell lymphoma with favorable prognosis and distinct gene expression signature: a report from the International DLBCL Rituximab-CHOP Consortium Program Study," (in eng), Blood, vol. 121, no. 14, pp. 2715-2724, 2013.

[13] J. H. Lee, Y. Kim, J. W. Choi, and Y. S. Kim, "Prevalence and prognostic significance of EpsteinBarr virus infection in classical Hodgkin's lymphoma: a meta-analysis," Arch Med Res, vol. 45, no. 5, pp. 41731, Jul 2014.

[14] Z. Mozaheb, "Epidemiology of Lymphoid Malignancy in Asia," Epidemiology Insights, Maria de Lourdes Ribeiro de Souza da Cunha, IntechOpen, 2012.

[15] X. Huang et al., "Epidemiology of classical Hodgkin lymphoma and its association with Epstein Barr virus in Northern China," PLoS One, vol. 6, no. 6, p. e21152, 2011.

[16] R. R. Makar, T. Saji, and T. A. Junaid, "Epstein-Barr virus expression in Hodgkin's lymphoma in Kuwait," Pathology Oncology Research, vol. 9, no. 3, p. 159, 2003/09/01 2003.

[17] T. C. Kwee, R. M. Kwee, and R. A. Nievelstein, "Imaging in staging of malignant lymphoma: a systematic review," Blood, vol. 111, no. 2, pp. 504-16, Jan 152008

[18] D. A. Eichenauer et al., "Hodgkin lymphoma: ESMO Clinical Practice Guidelines for diagnosis, treatment and follow-up," Ann Oncol, vol. 29, no. Suppl 4, pp. iv19-iv29, Oct 12018.

[19] P. G. Murray et al., "Effect of Epstein-Barr virus infection on response to chemotherapy and survival in
Hodgkin's disease," (in eng), Blood, vol. 94, no. 2, pp. 442-7, Jul 151999

[20] A. Carbone, A. Gloghini, A. Caruso, P. De Paoli, and R. Dolcetti, "The impact of EBV and HIV infection on the microenvironmental niche underlying Hodgkin lymphoma pathogenesis," Int J Cancer, vol. 140, no. 6, pp. 1233-1245, Mar 152017.

[21] P. P. Piccaluga et al., "Pathobiology of hodgkin lymphoma," Adv Hematol, vol. 2011, p. 920898, 2011.

[22] I. Shahab, J. P. Greer, T. A. Beeker, S. N. Wolff, R. D. Collins, and J. B. Cousar, "Recurrent Hodgkin's disease after bone marrow transplantation," (in eng), Am J Clin Pathol, vol. 107, no. 1, pp. 74-80, Jan 1997.

[23] M. Provencio, C. Salas, I. Millan, B. Cantos, A. Sanchez, and C. Bellas, "Late relapses in Hodgkin lymphoma: a clinical and immunohistochemistry study," (in eng), Leuk Lymphoma, vol. 51, no. 9, pp. 1686-91, Sep 2010.

[24] C. C. Su, H. H. Chiu, C. C. Chang, J. C. Chen, and S M. Hsu, "CD30 is involved in inhibition of T-cell proliferation by Hodgkin's Reed-Sternberg cells," (in eng), Cancer Res, vol. 64, no. 6, pp. 2148-52, Mar 15 2004.

[25] D. Aldinucci, A. Gloghini, A. Pinto, R. De Filippi, and A. Carbone, "The classical Hodgkin's lymphoma microenvironment and its role in promoting tumour growth and immune escape," J Pathol, vol. 221, no. 3, pp. 248-63, Jul 2010.

[26] Y. Liu, A. Sattarzadeh, A. Diepstra, L. Visser, and A van den Berg, "The microenvironment in classical Hodgkin lymphoma: an actively shaped and essential tumor component," Semin Cancer Biol, vol. 24, pp. 1522, Feb 2014

[27] A. Carbone, A. Gloghini, and C. Carlo-Stella, "Are EBV-related and EBV-unrelated Hodgkin lymphomas different with regard to susceptibility to checkpoint blockade?," Blood, vol. 132, no. 1, pp. 17-22, Jul 5 2018.

[28] M. G. Roemer et al., "PD-L1 and PD-L2 Genetic Alterations Define Classical Hodgkin Lymphoma and Predict Outcome," J Clin Oncol, vol. 34, no. 23, pp. 2690-7, Aug 102016.

[29] X. Wu et al., "B7-H1(PD-L1) confers chemoresistance through ERK and p38 MAPK pathway in tumor cells," bioRxiv, p. 308601, 2018.

[30] R. Chetty et al., "EBV latent membrane protein (LMP1) and bcl-2 protein expression in Reed-Sternberg-like cells in post-transplant lymphoproliferative disorders," (in eng), Histopathology, vol. 28, no. 3, pp. 257-60, Mar 1996.

[31] J. M. Martin, D. Veis, S. J. Korsmeyer, and B. Sugden, "Latent membrane protein of Epstein-Barr virus induces cellular phenotypes independently of expression of Bcl-2," (in eng), Journal of virology, vol. 67, no. 9, pp. 5269-5278, 1993.

[32] A. Gamboa et al., "Refractory and Relapse Predictive Biomarkers in Hodgkin Lymphoma and Potential Directed-Therapy Targets," Blood, vol. 132, pp. 28702870, 11/29 2018. 